\title{
Banco de sementes do solo de Caatinga submetida a plano de manejo florestal sustentável em Cuité-PB
}

\author{
Seed bank of Caatinga soil submitted to sustainable forest management plan in \\ Cuité-PB
}

Maílson Pereira de Souza' (D), Allyson Rocha Alves ${ }^{2}$ (D), Ivonete Alves Bakke ${ }^{3}$ (D), Josueldo Alves Lopes ${ }^{3}$ [D, Wellington de Sousa Santos ${ }^{3}$ (D), Emanoel Messias Pereira Fernando 3 (1)

${ }^{1}$ Universidade Federal Rural do Rio de Janeiro - UFRRJ. Seropédica, RJ, Brasil

2Universidade Federal Rural do Semiárido UFERSA - Mossoró, RN, Brasil

${ }^{3}$ Universidade Federal de Campina Grande - UFPB. Patos, PB, Brasil

\begin{abstract}
Como citar: Souza, M. P., Alves, A. R., Bakke, I. A., Lopes, J. A., Santos, W. S., \& Fernando, E. M. P. (2021). Banco de sementes do solo de caatinga submetida a plano de manejo florestal sustentável em cuité-pb. Scientia Forestalis, 49(130), e3494. https://doi.org/10.18671/scifor.v49n130.09
\end{abstract}

\section{Resumo}

Objetivou-se neste trabalho avaliar o banco de sementes do solo em uma área de caatinga manejada, sob diferentes idades de corte: Reserva Legal, UPA 2007, UPA 2012 e UPA 2014, localizadas no Assentamento da Reforma Agrária, Brandão III, Cuité-PB. Dez amostras de (serapilheira + solo) de cada área foram coletadas no interior de uma área de $25 \mathrm{~m}^{2}$ no canto inferior direito, utilizando um gabarito de ferro com dimensões de $30 \mathrm{~cm} \times 50 \mathrm{~cm} \times 3 \mathrm{~cm}$. O material foi acondicionado em bandejas de plástico com dimensões de $20 \mathrm{~cm} \times 14 \mathrm{~cm} \times 5 \mathrm{~cm}$ e levadas ao Viveiro Florestal da UFCG, Campus de Patos e mantidas sob tela de 50\% de sombreamento em regime de irrigação manual diária, durante um período experimental de sete meses. As espécies presentes foram depositadas no herbário da UFCG. Para diversidade florística foi estimado o índice de diversidade de Shannon-Weaver $\left(\mathrm{H}^{\prime}\right)$, equabilidade pelo Índice Pielou (J') e similaridade Sorensen (SO). A densidade de plântulas e a riqueza foram comparadas pelo Teste de Tukey a 5\%. Nas 40 bandejas oriundas das quatro unidades experimentais emergiram 1.993 indivíduos pertencentes a 22 famílias botânicas e 49 espécies. A diversidade de Shannon-Weaver $\left(\mathrm{H}^{\prime}\right)$, encontrada para as quatro unidades experimentais foram: 2,33 nats. ind ${ }^{-1}, 0,99{\text { nats. } \text { ind }^{-1} \text {, 2,19 nats.ind }}^{-1}$ e 1,35 nats.ind ${ }^{-1}$ para Reserva Legal, UPA 2007, UPA 2012 e UPA 2014. Os bancos de sementes nas três áreas de caatinga manejada são compostos predominantemente por espécies herbáceas. As áreas se mostraram semelhantes em respeito ao índice de similaridade.

Palavras-chave: Emergência de plântulas; Regeneração; Herbáceo.

\begin{abstract}
The objective of this work was to evaluate the soil seed bank in a managed caatinga area, under different cutting ages: Legal Reserve, UPA 2007, UPA 2012 and UPA 2014, located in the Agrarian Reform Settlement, Brandão III, Cuité-PB. Ten samples of litter (soil + soil) from each area were collected inside an area of $25 \mathrm{~m}^{2}$ in the lower right corner, using an iron template of $30 \mathrm{~cm} \times 50 \mathrm{~cm} \times 3 \mathrm{~cm}$. The material was packed in plastic trays with $20 \mathrm{~cm} \times 14 \mathrm{~cm} \times 5 \mathrm{~cm}$ and taken to the Forest Nursery of the UFCG, Campus of Patos and kept under 50\% shading under daily manual irrigation during an experimental period of seven months. The species present were deposited in the UFCG herbarium. For floristic diversity, the diversity index of Shannon-Weaver $(\mathrm{H}$ '), equability by the Pielou Index (') and Sorensen (SO) similarity were estimated. Seedling density and richness were compared by the Tukey test at 5\%. In the 40 trays from the four experimental units emerged 1,993 individuals belonging to 22 botanical families and 49 species. The Shannon-Weaver index ( $(\mathrm{H})$, found for the four experimental units were: 2.33 nats. ind $^{-1}, 0.99$ nats.ind-1, 2.19 nats.ind- 1 and 1.35 nats.ind-1 for Legal Reserve, UPA 2007, UPA 2012 and UPA 2014. The seed bank in the three areas of managed caatinga are composed predominantly by herbaceous species. The areas were similar in respect to the index of similarity.
\end{abstract}

Keywords: Seedling emergence; Regeneration; Herbaceous.

Fonte de financiamento: Coordenação de Aperfeiçoamento de Pessoal de Nível Superior - Brasil (CAPES) - Código de Financiamento 001

Conflito de interesse: Nada a declarar.

Autor correspondente: mailsonflorasertao@gmail.com

Recebido: 15 outubro 2019.

Aceito: 2 junho 2020.

Editor: Paulo Henrique Müller Silva.

(c) Este é um artigo publicado em acesso aberto (Open Access) sob a licença Creative Commons Attribution, que permite uso, distribuição e Este é um artigo publicado em acesso aberto (Open Access) sob a licença Creative Commons Attribution,
reprodução em qualquer meio, sem restrições desde que o trabalho original seja corretamente citado. 


\section{INTRODUÇÃO}

O conhecimento dos mecanismos responsáveis pela recuperação dos ecossistemas florestais é indispensável, especialmente quando se percebe que a degradação provocada pela pressão populacional aumenta consideravelmente, em decorrência do uso dos recursos naturais. Ribeiro et al. (2017), enfatizam que, as ações antrópicas no Nordeste brasileiro, como a retirada e queima da vegetação nativa e atividades agropecuárias, estão entre as principais responsáveis pela degradação ambiental e perda da biodiversidade da região.

A sustentabilidade ecológica em plano de manejo florestal sustentável é assunto bastante debatido, sobretudo, quando o bioma em destaque é a Caatinga. De maneira geral estudos ainda não trazem uma conclusão concreta a respeito da ameaça a biodiversidade florística, devido à Caatinga apresentar grande heterogeneidade em relação aos fatores edafoclimáticos que moldam esse bioma assim como as respostas aos diferentes distúrbios (Riegelhaupt et al., 2010; Pareyn et al., 2015). Dessa forma, torna-se importante a busca por pesquisas sobre a dinâmica florestal, ou seja, como as áreas impactadas se recuperam após um distúrbio, possibilitando a adoção e criação de estratégias que possam diminuir as incertezas que dizem respeito a sustentabilidade de áreas sob plano de manejo.

A regeneração natural é um dos principais mecanismos responsáveis pela dinâmica florestal, pois é através deste processo que os ecossistemas florestais se reestabelecem após um distúrbio. O sucesso desse mecanismo depende diretamente da rebrota de cepas após o corte garantindo a sobrevivência e o desenvolvimento de boa parte dos indivíduos que irão compor os estágios mais avançados de sucessão (Martins et al., 2012; Lucena et al., 2016). Dentre os processos envolvidos na regeneração de florestas, a dinâmica do banco de sementes desempenha um papel importante no transporte das sementes, possibilitando a formação de novas florestas primárias e secundárias, recompondo áreas anteriormente exploradas por seres humanos (Golos \& Dixon, 2014; Santos et al., 2016).

O entendimento a respeito do banco de sementes do solo torna-se uma das principais estratégias utilizadas para recuperar um ecossistema após intervenção antrópica. Schorn et al. (2013), definem o banco de sementes no solo como sendo o conjunto de sementes viáveis, que estejam no solo e/ou associadas à serapilheira em um determinado momento. O mesmo é considerado um sistema dinâmico, variando de acordo com a entrada e saída de sementes (Ribeiro et al., 2017).

O conhecimento do banco de sementes permite que se realizem previsões sobre o potencial florístico existente no processo de sucessão de uma determinada área. Desse modo, informações sobre o banco de sementes são essenciais para o gerenciamento e implantação de planos de manejo e de recuperação florestal (Nóbrega et al., 2009). De acordo com Parente et al. (2011), informações referentes à densidade e composição florística do banco de sementes no bioma Caatinga são instrumentos indispensáveis na identificação da riqueza das espécies herbáceas e sua regeneração no bioma, após o uso pela agricultura ou distúrbios antrópicos. Estudos enfatizam que o entendimento desses processos requer o conhecimento de informações da vegetação e pode ser fundamental para o planejamento do manejo e para a aplicação de práticas silviculturais direcionadas ao uso sustentável de determinada área (Ferreira et al., 2014, 2017).

Nas últimas décadas, houve um aumento no número de estudos com a finalidade de avaliar e entender as possíveis respostas do banco de sementes do solo em relação ao uso e ocupação do solo (Santos et al., 2013; Mendes et al., 2014; Santos et al., 2016; Sousa et al., 2017). Mesmo assim, as informações geradas ainda são incipientes, devido à grande variação ambiental encontrada nas diferentes fitofisionomias da Caatinga. Baseado nisso Ferreira et al. (2014), enfatizam que o banco de sementes ainda é pouco estudado quanto à composição florística e ao número de indivíduos, principalmente em áreas que sofreram intervenção e estão em diferentes estágios de regeneração natural. A ausência desses estudos é mais preocupante quando se trata do manejo sustentável na Caatinga.

Poucos estudos foram desenvolvidos objetivando a obtenção de informações acerca do efeito de diferentes tipos de manejos e distúrbios no banco de sementes do solo em ambientes semiáridos. Mendes et al. (2014) estudando uma área de floresta seca que foi convertida em 
área agrícola, mas logo após foi abandonada se regenerando há 17 anos e comparando-a com uma área vizinha não explorada, concluíram que a riqueza e a densidade de sementes foram significativamente maiores no remanescente florestal. Os mesmos autores enfatizam que em 17 anos de regeneração natural (área em pousio) recuperou parte da composição florística, riqueza de espécies, densidade do banco de sementes do solo, mas estas características ainda são inferiores às registradas no remanescente florestal (área não explorada).

No mesmo sentido, Araújo et al. (2014) estudando a influência do status da floresta e da variação sazonal sobre o banco de sementes no semiárido brasileiro, constataram que composição florística da floresta jovem foi diferente da madura. Além disso, os autores observaram que o quantitativo de espécies, bem como o número de sementes no banco do solo foi maior na floresta madura em comparação com a jovem. Os resultados desse estudo mostraram que o banco de sementes da floresta madura armazena espécies que não conseguem se estabelecer na floresta jovem. Esses resultados provavelmente são devido à exigência de determinadas condições, como menor temperatura e maior nível de sombreamento que desencadeiam o processo germinativo das sementes.

Baseado no exposto o presente estudo tem como hipóteses: 1- a exploração da vegetação caatinga através do plano de manejo sustentável utilizando práticas e estratégias próprias modificam a riqueza, a composição florística e a densidade de sementes germinada do banco de sementes do solo; 2- O tempo decorrido entre a exploração manejada e observação influencia a densidade, florística e a riqueza do banco de sementes do solo. Assim este estudo teve como objetivo avaliar o banco de sementes do solo em uma área de caatinga manejada, sob diferentes idades de corte: Reserva Legal, UPA 2007, UPA 2012 e UPA 2014.

\section{MATERIAL E MÉTODOS}

\section{Caracterização das áreas}

A área de pesquisa fica localizada acerca de $20 \mathrm{~km}$ da sede municipal de Cuité, compreendida entre as coordenadas $06^{\circ} 27^{\prime} 36^{\prime \prime S}$ e $36^{\circ} 02^{\prime} 54$, "W, com aproximadamente 1.384 hectares, sendo $50 \%$, destinados ao manejo florestal sustentável. A área encontra-se subdividida em 45 lotes individuais, uma área comunitária e a Reserva Legal. Os lotes estão distribuídos em 20 Unidades de Produção Anual (UPA's), com área média de 25,9 ha/UPA. O plano de Manejo Florestal Sustentável foi implantado em 2006.

As quatro áreas escolhidas para o desenvolvimento do estudo estão inseridas no plano de manejo sustentável. A primeira área é referente à Reserva Legal com aproximadamente 276,93 ha, a segunda é a UPA 04 correspondendo à unidade de produção anual explorada em 2007 (dez anos em pousio), com aproximadamente 27,9 ha. A terceira área foi a UPA 13 (cinco anos em pousio), com área aproximada de $27,3 \mathrm{ha}$, designada UPA 2012 e a quarta área foi a UPA 02 (três anos em pousio), denominada UPA 2014, cuja exploração aconteceu no ano de 2014 com cerca de 29,2 há.

O tipo de solo é classificado, conforme análise do Mapa Exploratório - Reconhecimento de Solos do Estado da Paraíba de 1971 (Jacomine et al., 1972): uma associação do tipo NEOSOLO LITÓLICO, textura arenosa e/ou média fase pedregosa e ARGISSOLO VERMELHOAMARELO DISTRÓFICO (Santos et al., 2013).

A propriedade Brandão III apresenta uma vegetação de caatinga hiperxerófila do tipo T4 - Vegetação Arbórea Fechada (Superintendência de Administração do Meio Ambiente, 2004), formada por uma vegetação lenhosa densa, dominante, com porte variando entre 6 e 10 metros, com um estoque madeireiro estimado, para a mesorregião da Borborema, em 205,09 st/ha (Silva, 1994).

\section{Coleta de solo e serapilheira para estudo do banco de sementes}

Para avaliar o banco de sementes nas áreas selecionadas, foram escolhidas de forma aleatória, dez parcelas de $5 \times 5\left(25 \mathrm{~m}^{2}\right)$ dentro de cada unidade experimental. No interior de cada 
parcela, no canto inferior direito, foram coletadas 10 amostras do banco de sementes do solo, totalizando 40 amostras de solo + serapilheira. Para coleta do material foi utilizado um gabarito de ferro nas dimensões $30 \mathrm{~cm} \times 50 \mathrm{~cm} \times 3 \mathrm{~cm}$, coletando todo material que se encontrava no seu interior (serapilheira + solo), até cerca de três centímetros de profundidade.

As amostras de solo coletadas foram acondicionadas em sacos plásticos, etiquetadas com o controle da parcela e transportadas para o Viveiro Florestal da Universidade Federal de Campina Grande (UFCG)/Centro de Saúde e Tecnologia Rural (CSTR)/Unidade Acadêmica de Engenharia Florestal (UAEF), Patos, PB.

\section{Instalação do experimento}

O material de cada parcela, coletado no mês de janeiro de 2017, foi acondicionado em bandejas de plástico com dimensões de $20 \mathrm{~cm} \times 14 \mathrm{~cm} \times 5 \mathrm{~cm}$, perfuradas para drenar o excesso de água. As mesmas foram dispostas aleatoriamente em bancadas, localizadas em ambiente protegido com tela de $50 \%$ de sombreamento, sendo irrigadas diariamente com regador manual durante o período experimental de sete meses (01 de fevereiro à 01 de outubro).

O método utilizado para determinar a densidade de sementes no banco de sementes do solo foi o da emergência de plântulas (não considerando a densidade de sementes dormentes na amostra), seguindo a metodologia adotada por Silva \& Azevedo (2016). As contagens das plântulas de todos os hábitos, emergidas foram realizadas durante o período de sete meses, em intervalos semanais. As plântulas foram acompanhadas desde a emergência até o momento da floração, sendo retiradas para impedir a dispersão de propágulos e superestimar a densidade do banco. O material fértil de todas as plantas foi fotografado, coletado, herborizado e depositado no Herbário da UFCG para posterior identificação taxonômica. A identificação das espécies foi realizada com auxílio de taxonomistas, literaturas especializadas e comparações com exsicatas depositadas no herbário, de acordo com o Angiosperm Phylogeny Group (2009). Os nomes científicos foram verificados partir de consultas à Flora do Brasil (Jardim Botânico do Rio de Janeiro, 2020).

A identificação das espécies arbóreas foi realizada através de comparação de morfologia de plântulas, realizada pelos especialistas do herbário, uma vez que, não pode ser coletado o material fértil para identificação taxonômica.

Após cinco meses experimentais (01 de fevereiro à 01 de julho), quando não se observou mais emergência de plântulas durante sete dias consecutivos, todas as bandejas foram retiradas das bancadas, acondicionadas em ambiente protegido do sol, vento e água e submetidas ao déficit hídrico. Nesse período revolveu-se o solo com objetivo de permitir que as sementes que se encontravam nas camadas inferiores se deslocassem para as superficiais, podendo ocasionar dessa forma, a emergência de novas plântulas após a retomada da irrigação.

A riqueza e a abundância das espécies de cada área foram avaliadas utilizando o Índice de Diversidade de Shannon-Wiener $\left(\mathrm{H}^{\prime}\right)$. A distribuição dos indivíduos entre as espécies foi analisada pelo Índice de Uniformidade de Pielou (J) e para análise da similaridade florística utilizou-se o índice de Similaridade de Sorensen.

\section{Análise de dados e desenho experimental}

Considerando-se cada Unidade de produção anual (UPA2007, UPA2012, UPA2014) como diferentes tratamentos, haja vista terem tempo de recuperação diferente (10, 5 e 3 anos) e a Reserva Legal como testemunha (ausente de corte). Cada amostra foi considerada como uma repetição (10 amostras) para cada área.

Assim foram conferidas as preposições de normalidade e homocedasticidade e, quando possível, a análise foi realizada através de análise de variância (teste de F) e comparação de médias pelo teste de Tukey para as variáveis, densidade e riqueza. As análises foram realizadas com auxílio do pacote estatístico ASSISTAT Versão 7.7 beta (Silva, 2016), ao nível de significância de 5\%. 


\section{RESULTADOS E DISCUSSÃO}

\section{Emergência das plântulas}

As sementes começaram a germinar a partir do terceiro dia após a instalação do experimento (01 de fevereiro). Todas as áreas estudadas apresentaram comportamento semelhante para a germinação. Notou-se aumento contínuo no número de indivíduos nas primeiras semanas de avaliação. Nas semanas seguintes, o aparecimento de novos indivíduos foi gradativamente diminuindo, até a não ocorrência de emergência das sementes (Figura 1). Observou-se que $53,68 \%$ das sementes germinaram nos três primeiros meses. Até o terceiro mês houve um aumento no número de sementes germinadas, a partir daí a germinação apresentou irregularidade, mesmo mantendo as mesmas condições experimentais.

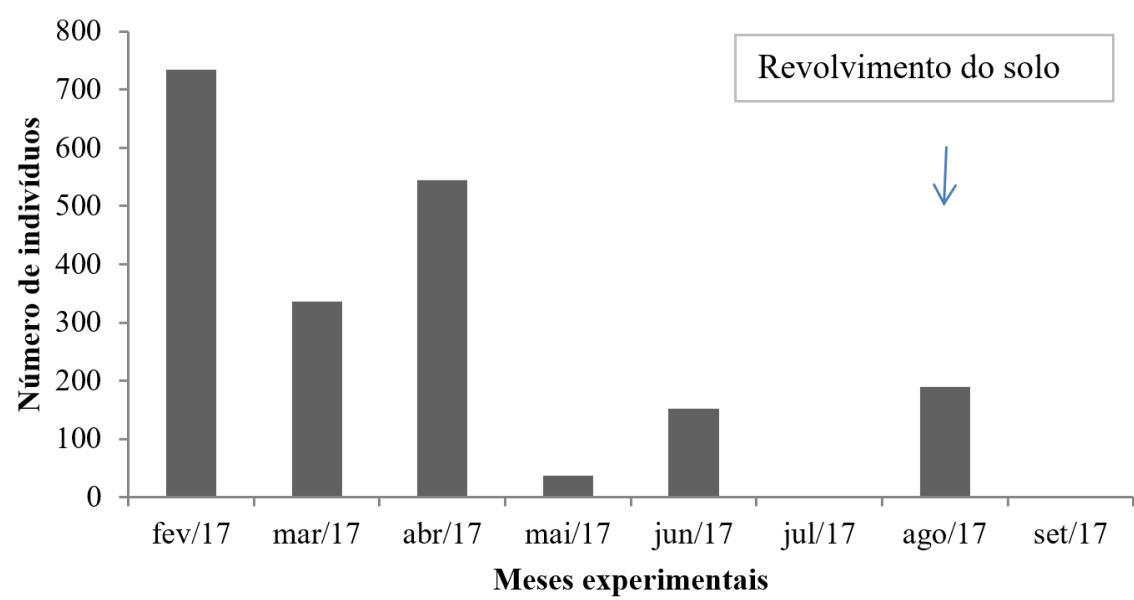

Figura 1. Número de indivíduos emergidos no banco de sementes do solo (solo+serapilheira), nas unidades de produção anuais (UPA's) e Reserva Legal em uma área submetida a plano de manejo sustentável, Cuité-PB.

A emergência das plântulas favorecida pela irrigação diária, normalmente é observada em ambientes naturais. Para Costa e Araújo (2003), isso se dá logo nas primeiras chuvas, uma vez que a paisagem, em sua maioria seca, é transformada pelo surgimento de um grande número de novas plântulas, que emergem em decorrência das boas condições climáticas que caracterizam o início do período chuvoso.

Esta rápida resposta às condições favoráveis pode ser uma estratégia das plantas da Caatinga para garantir maior sobrevivência e crescimento durante o período chuvoso, tornando-as mais fortalecidas, isso ocorre devido os primeiros indivíduos germinados terem maior exposição às condições climáticas favoráveis, como é o caso da precipitação, tornandoos mais vigorosos para enfrentar as condições de seca subsequentes. Para Bakke et al. (2006), e Santos et al. (2013) a germinação das sementes da Caatinga ocorre no início da estação chuvosa evidenciando a influência da sazonalidade das chuvas para a germinação e recrutamento do maior número possível de indivíduos.

Este comportamento influenciado pela sazonalidade garante um balanço positivo para germinação, favorecendo o estabelecimento de muitos indivíduos em relação à morte daqueles que completaram o ciclo de vida ou sofreram alguma injúria. Este dado reforça que as sementes terófitas da caatinga apresentam rápida germinação no início da estação chuvosa, característica que favorece a permanência no ambiente, visto que essa estação é curta, sendo em alguns anos, por apenas três meses (Ferreira et al., 2014).

O déficit hídrico e o revolvimento do solo realizados no mês de julho, após a ausência de emergência de plântulas por sete dias consecutivos, deve ter promovido a exposição das sementes mais profundas às condições de maior luminosidade na superfície, sendo este fator responsável pela emergência de 9,48\% das plântulas. Esse comportamento acontece sempre 
que há sementes fotoblásticas positivas, ou seja, que são estimuladas pelo aumento da intensidade da luz, outro fator que também pode influenciar nesse comportamento é também ocorrência de dormência secundária pelo longo tempo no escuro, podendo ocorrer mesmo com sementes indiferentes à luz (Baskin \& Baskin, 2005).

Esse efeito torna-se evidente quando há o aparecimento de novas espécies como foi o caso da espécie Senna macranthera, surgindo somente após o revolvimento do solo. Não obstante, outros fatores também podem estar ligados a esse evento, como a presença de dormência em sementes de algumas espécies. Fortalecendo essa justificativa, Martins et al. (2011), relata que o aparecimento de novas plântulas após o período de estresse hídrico, provavelmente é devido a ocorrência de herbáceas pioneiras no solo, bem como de outras formas de vida que apresentam sementes com dormência facultativa, mecanismo que garante a sua sobrevivência.

Os resultados encontrados mostraram-se semelhantes aos obtidos por Gonçalves et al. (2011), que avaliando o banco de sementes do solo de uma área de Caatinga sujeita a alagamento sazonal no município de Sossego-PB, invadida por Parkinsonia aculeata L., encontraram 76\% de germinação nas primeiras 20 semanas. Já Costa \& Araújo (2003), examinando o banco de sementes em serapilheira coletada no final da estação seca no município de Quixadá-CE, obtiveram mais de $88 \%$ da germinação nas quatro primeiras semanas.

A hipótese que explica a explosão na germinação de sementes é evidenciada por Baskin \& Baskin (2005) ao relatarem que esse mecanismo acontece devido à presença de sementes quiescentes, cuja germinação depende das condições climáticas ideais, como disponibilidade de água e temperatura. Outra justificativa para essa observação é que segundo Santos et al. (2016), a variação sazonal na precipitação influencia o comportamento do banco de sementes do solo, assim a composição florística, a riqueza de espécies e a densidade do banco de sementes do solo, são moldados por esse fator. Esse fato segue o padrão das florestas secas, pois a composição, a riqueza e a densidade de sementes mudam mais rapidamente com a variação sazonal nesses ambientes (Santos et al., 2010; Mendes et al., 2014).

Nas 40 bandejas oriundas das quatro unidades experimentais emergiram 1.993 indivíduos pertencentes a 22 famílias botânicas e 49 espécies (Tabela 1). Desse total de indivíduos, 302, 587, 392 e 712 foram, respectivamente, observados no material (serapilheira+solo) da Reserva Legal (RL), na UPA 2007, UPA 2012 e UPA 2014.

Tabela 1. Número de famílias, espécies e indivíduos que emergiram nas amostras de (serapilheira+solo) nas unidades de produção anuais (UPA's) e Reserva Legal em uma área submetida a plano de manejo sustentável, Cuité-PB

\begin{tabular}{|c|c|c|c|c|}
\hline Famílias/Espécies & $\mathbf{R L}$ & UPA 2007 & UPA 2012 & UPA 2014 \\
\hline Famílias por área & 15 & 14 & 14 & 17 \\
\hline Famílias comuns & \multicolumn{4}{|c|}{21} \\
\hline Espécies por área & 26 & 22 & 28 & 27 \\
\hline Total de espécies & \multicolumn{4}{|c|}{49} \\
\hline Indivíduos por área & 302 & 587 & 392 & 712 \\
\hline Indivíduos $/ \mathrm{m}^{2}$ & $201,33 b$ & 391,33ab & $261,33 a b$ & $474,66 a$ \\
\hline Total de indivíduos & \multicolumn{4}{|c|}{1993} \\
\hline
\end{tabular}

Valores seguido na sexta linha pela mesma letra não diferem estatisticamente pelo Teste de Tukey ao nível de 5\% de significância.

Estes números quando estimados para $\mathrm{m}^{2}$ equivalem, respectivamente, a 201,33, 391,33, 261,33 e 474,66 o que totaliza 1328,65 sementes viáveis por $\mathrm{m}^{2}$. O resultado referente à densidade total aqui expresso quando comparado ao de Ferreira et al., (2017) se mostrou inferior, esses autores estudando a fitossociologia do banco de sementes em diferentes estágios de regeneração natural da vegetação, no Seridó paraibano encontraram resultados referentes a serapilheira e no solo com valores de 5.066 sementes $/ \mathrm{m}^{2}$ e 3.939 sementes $/ \mathrm{m}^{2}$, respectivamente. 
Os resultados encontrados por Ribeiro et al, (2017) também foram superiores aos aqui apresentados, assim esses autores avaliando a diversidade do banco de sementes em três áreas de Caatinga manejadas no semiárido da Paraíba encontraram 2.219, 1.967, 3.023 e 1.666 sementes viáveis por $\mathrm{m}^{2}$, referentes a área com plantio de craibeiras (A1), área degradada (A2) e área com plantio de jurema +sabiá (A3), respectivamente.

O teste Tukey a ( $5 \%$ de significância) demonstrou que o número de indivíduos presentes na UPA 2014 diferenciou-se estatisticamente apenas da RL e que as demais médias dos tratamentos não diferenciaram entre si.

O maior número de sementes germinadas na UPA 2014 pode ser atribuído ao baixo porte da vegetação regenerante, bem como a densidade vegetativa, ocasionando diretamente na formação de copa e consequentemente no sombreamento. Assim, uma vez que esta área está há apenas três anos em processo de recuperação, o que influencia diretamente na incidência de raios solares, responsáveis pela ativação das sementes de espécies do estrato herbáceo, que se desenvolvem e realizam a dispersão dos diásporos.

Esse resultado é fortalecido com as observações feitas por Ferreira et al. (2017) que atribuíram o maior número de sementes germinadas a uma área de pastagem nativa, enfatizando que a ausência de espécies arbustivas e arbóreas, permitiu maior incidência luminosa e favoreceu o desenvolvimento das espécies herbáceas, comprovado pela germinação das sementes destas espécies em estudos de banco de sementes em áreas em diferentes processos de recuperação.

Torna-se importante relatar que resultados diferentes foram observados por Araújo et al. (2014) e Mendes et al. (2014), que estudando uma área de floresta seca explorada para fins agrícolas, e abandonada em seguida, se regenerando há 17 anos e comparando-a com uma área vizinha não explorada, concluíram que a densidade de sementes foram significativamente maiores no remanescente florestal do que na área em pousio. Já, Araújo et al. (2014) estudando a influência do status da floresta e da variação sazonal sobre o banco de sementes no semiárido brasileiro, constataram que a composição florística da floresta jovem se difere da madura. Dessa forma os dois trabalhos enfatizam que banco de sementes da floresta madura armazena espécies que não conseguem se estabelecer na floresta jovem, possibilitando maior riqueza e maior densidade no banco de sementes da floresta madura. No entanto, Ribeiro et al. (2017), afirmam que banco de sementes possui dinâmica própria que varia conforme a espécie, condições da semente, ocorrência de predadores e fatores ambientais, e que seu tamanho é determinado pela produção de sementes, extensão da chuva de sementes, mortalidade de sementes no solo e número de sementes germinadas. Assim, torna-se incerto e inseguro enquadrar todos os ambientes de caatinga em um mesmo padrão de comportamento do banco de sementes do solo.

Por outro lado, verifica-se ainda que as áreas que estão em processo de recuperação há mais tempo, a exemplo das UPA 2007 e UPA 2012, apresentaram decréscimos em relação ao número de sementes $/ \mathrm{m}^{2}$. Isso se dá provavelmente pela redução da luminosidade imposta pela presença de indivíduos arbóreos e arbustivos, o que dificulta o desenvolvimento do estrato herbáceo, devido à competição e o excesso de sombreamento estabelecido pelos estratos superiores. Observações feitas por Araújo et al. (2001) que estudando florestas sucessionais em diferentes estágios serais de desenvolvimento, das quais foram selecionadas três idades para estudo do banco de sementes (6, 17 e 30 anos, após exploração), constataram que a maior densidade de sementes no solo ocorreu nas florestas sucessionais mais jovens, que apresentaram sementes, principalmente, de espécies pioneiras formadoras típicas do banco de sementes persistente.

Quando observado o valor referente à $\mathrm{RL}$, correspondendo a área sem nenhuma exploração, percebe-se que a premissa de que a exploração manejada e o grau de conservação na qual se encontra a unidade experimental pode influenciar negativamente a densidade do banco se sementes, é sustentada de maneira mais sólida.

Portanto, o estado de preservação (isenta de corte) desta unidade experimental pode ser considerado o fator limitante para a densidade de indivíduos. Assim a presença de espécies arbustivas e arbóreas, bem como uma estrutura vertical mais heterogênea, constituem 
barreiras físicas que dificultam a dispersão das sementes, especialmente, as do estrato herbáceo, uma vez que diminui a velocidade do vento, influenciando diretamente na dispersão de sementes que na sua maioria, é anemocórica (Ribeiro et al., 2017). Nesse mesmo sentido, Andrade (2013) afirma que o sombreamento proporcionado pelas plantas lenhosas oportuniza o desenvolvimento de microhabitats com maior ou menor incidência luminosa, constituindo um fator relevante para o estabelecimento de espécies herbáceas.

\section{Composições do Banco de Sementes e formas de vida}

Na UPA 2007, foram encontradas 22 espécies distribuídas em 15 famílias, na UPA 2012 estiveram presentes 28 espécies distribuídas em 15 famílias, na UPA 2014 foram catalogadas 28 espécies distribuídas em 18 famílias, já na Reserva Legal 26 espécies estiveram presentes, estando estas distribuídas em 16 famílias. Das 49 espécies, seis não foram identificadas (Tabela 2).

Tabela 2. Famílias e espécies presentes nas amostras de (serapilheira+solo) nas unidades de produção anuais (UPA's) e Reserva Legal em uma área submetida a plano de manejo sustentável, Cuité-PB

\begin{tabular}{|c|c|c|c|c|c|}
\hline Família/Espécie & FV & $\begin{array}{l}\text { UPA } \\
2007\end{array}$ & $\begin{array}{l}\text { UPA } \\
2012\end{array}$ & $\begin{array}{l}\text { UPA } \\
2014\end{array}$ & R.L \\
\hline \multicolumn{6}{|l|}{ Amaranthaceae } \\
\hline Alternanthera tenella Colla & Erv & $x$ & & $x$ & $x$ \\
\hline Gomphrena sp & Subar & $x$ & & & \\
\hline Morfoespécie 7 & Erv & $x$ & $x$ & $x$ & \\
\hline \multicolumn{6}{|l|}{ Anacardiaceae } \\
\hline Myracrodruon urundeuva Allemao & Árv & $x$ & & $x$ & $x$ \\
\hline \multicolumn{6}{|l|}{ Asteraceae } \\
\hline Bidens pilosa $\mathrm{L}$ & Erv & $x$ & & $x$ & $x$ \\
\hline Centratherum punctatum Cass. & Erv & & $x$ & $x$ & \\
\hline \multicolumn{6}{|l|}{ Boraginaceae } \\
\hline Heliotropium indicum L. & Erv & $x$ & & & \\
\hline \multicolumn{6}{|l|}{ Commelinaceae } \\
\hline Commelina erecta $\mathrm{L}$. & Erv & $x$ & $x$ & $x$ & $x$ \\
\hline Tinantia sprucei C.B. Clarke & Erv & $x$ & $x$ & $x$ & $x$ \\
\hline \multicolumn{6}{|l|}{ Cleomaceae } \\
\hline Cleome affinis DC. & Erv & & & $x$ & \\
\hline \multicolumn{6}{|l|}{ Convolvulaceae } \\
\hline Ipomoea nil (L.) Roth. & Trep & $\mathrm{X}$ & $x$ & & $x$ \\
\hline Ipomoea minutiflora (M. Martens \& Galeotti House). & Trep & & $x$ & & \\
\hline Jacquemontia corymbulosa Benth. & Trep & & & $x$ & \\
\hline \multicolumn{6}{|l|}{ Cyperaceae } \\
\hline Cyperus difformis L. & Erv & $x$ & & $x$ & \\
\hline Cyperus odoratus L. & Erv & & $x$ & & $x$ \\
\hline \multicolumn{6}{|l|}{ Euphorbiaceae } \\
\hline Acalypha villosa Jacq. & Arb & & $x$ & & \\
\hline Croton blanchetianus Baill & Árv & & & & $x$ \\
\hline Euphorbia hirta $\mathrm{L}$ & Erv & & $x$ & $x$ & \\
\hline Jatropha mollissima (Pohl) Baill. & Árv & & & & $x$ \\
\hline Manihot glaziovii Müll. Arg. & Arb & & & & $x$ \\
\hline Morfoespécie 2 & Erv & $x$ & $x$ & $x$ & $x$ \\
\hline \multicolumn{6}{|l|}{ Fabaceae } \\
\hline Piptadenia stipulacea (Benth.) Ducke & Árv & & $x$ & & $x$ \\
\hline
\end{tabular}


Tabela 2. Continua...

\begin{tabular}{|c|c|c|c|c|c|}
\hline Família/Espécie & FV & $\begin{array}{l}\text { UPA } \\
2007\end{array}$ & $\begin{array}{l}\text { UPA } \\
2012\end{array}$ & $\begin{array}{l}\text { UPA } \\
2014\end{array}$ & R.L \\
\hline $\begin{array}{c}\text { Senna macranthera (DC. ex Collad.) H.S.Irwin \& } \\
\text { Barneby }\end{array}$ & Arb & $x$ & & & \\
\hline $\begin{array}{c}\text { Chamaecrista duckeana (P. Bezerra \& Afr. Fern.) H.S. } \\
\text { Irwin \& Barneby }\end{array}$ & Subar & & & $x$ & \\
\hline $\begin{array}{l}\text { Centrosema brasilianum (L.) Benth. } \\
\text { Lamiaceae }\end{array}$ & Trep & $x$ & $x$ & $x$ & $x$ \\
\hline $\begin{array}{l}\text { Marsypianthes chamaendrys (Vahl) Kuntze } \\
\text { Malvaceae }\end{array}$ & Erv & $x$ & $x$ & $x$ & $x$ \\
\hline Briquetia spicata (Kunth) Fryxell & Arb & & & & $x$ \\
\hline Herissantia tiubae (K.Schum.) Brizicky & Subar & & $\mathrm{x}$ & $x$ & \\
\hline Corchorus argutus Kunth & Subar & $x$ & $\mathrm{x}$ & & \\
\hline $\begin{array}{c}\text { Pseudobombax marginatum (A.St.-Hil., Juss. \& } \\
\text { Cambess.) A.Robyns }\end{array}$ & Árv & & & & $x$ \\
\hline $\begin{array}{l}\text { Malvastrum tomentosum (L.) S.R. Hill of } \\
\text { Molluginaceae }\end{array}$ & Erv & & $x$ & & $x$ \\
\hline $\begin{array}{l}\text { Mollugo verticillata } \mathrm{L} \\
\text { Onagraceae }\end{array}$ & Erv & $x$ & $x$ & $x$ & $x$ \\
\hline $\begin{array}{l}\text { Ludwigia octovalvis (Jacq.) P.H.Raven: } \\
\text { Oxalidaceae }\end{array}$ & Erv & & & $x$ & $x$ \\
\hline $\begin{array}{l}\text { Oxalis divaricata Mart. Ex Zucc } \\
\text { Phyllantgaceae }\end{array}$ & Erv & & $x$ & $x$ & $x$ \\
\hline $\begin{array}{l}\text { Phyllantus niruni L. } \\
\text { Poaceae }\end{array}$ & Erv & $x$ & & $x$ & $x$ \\
\hline Brachiaria decumbens Stapf & Erv & $x$ & $x$ & $x$ & $x$ \\
\hline Cenchrus ecchinatus L & Erv & & $x$ & & \\
\hline Eleusine indica $(\mathrm{L})$ Gaertn & Erv & & $x$ & $x$ & $x$ \\
\hline $\begin{array}{l}\text { Morfoespécie } 3 \\
\text { Portulacaceae }\end{array}$ & Erv & & $x$ & $x$ & $x$ \\
\hline Portulaca elatior Mart. & Erv & $x$ & & $x$ & \\
\hline Portulaca oleracea L & Erv & $x$ & $\mathrm{X}$ & $x$ & \\
\hline $\begin{array}{l}\text { Talinum paniculatum (Jacq.) Gaertn. } \\
\text { Rubiaceae }\end{array}$ & Erv & & $\mathrm{X}$ & $x$ & $x$ \\
\hline Espermacoce sp & Erv & & $x$ & & \\
\hline Plantaginaceae & & & & & \\
\hline $\begin{array}{l}\text { Scoparia dulcis L. } \\
\text { Solanaceae }\end{array}$ & Erv & & & & $x$ \\
\hline Schwenckia americana Rooyen ex L. & Erv & & $x$ & $x$ & \\
\hline Salum sp. & Erv & & $\mathrm{x}$ & $x$ & \\
\hline Indeterminada & Erv & & & & \\
\hline Moefoespécie 5 & Erv & $x$ & & & \\
\hline Morfoespécie 6 & Erv & $x$ & & & \\
\hline Morfoespécie 1 & Erv & & $\mathrm{X}$ & & \\
\hline
\end{tabular}

Em que: FV: Forma de vida (Erv: Erva, Arb: Arbusto, Árv: árvore, Subarb: subarbusto e Trep: Trepadeira.

O número de espécies encontrado neste trabalho se mostrou inferior aos relatados por Gonçalves et al. (2011), que estudando o banco de sementes em três ambientes distintos de Caatinga encontraram 130 espécies distribuídas em 28 famílias e 91 gêneros. Sousa et al. 
(2017) avaliando a florística e a fitossociologia do banco de sementes do solo de Caatinga invadida por Cryptostegia madagascariensis Bojer ex Decne, encontraram 71 espécies, 18 famílias e 46 gêneros. Paz et al. (2016), com objetivo de analisar e comparar o banco de sementes em áreas de Caatinga com diferentes graus de antropização, visando diagnosticar a influência na composição do mesmo encontraram 40 espécies distribuídas em 17 famílias. Essas comparações ajudam a compreender que com o aumento da perturbação, espera-se que o ambiente apresente maior diversidade de sementes de espécies (Schippers et al, 2001).

É importante ressaltar que todos os trabalhos anteriormente citados, tinham como característica marcante a presença de espécies invasoras e mesmo assim, as amostras de solo coletadas, se mostraram mais diversas. Não obstante, os valores aqui expressos para as diferentes unidades experimentais mostraram comportamento diferente, ressaltando que, quanto mais conservada (isenta de corte ou maior tempo em pousio), menor foi à quantidade de espécies encontradas. Este fato deve-se provavelmente a menor quantidade de espécies herbáceas presentes nestes ambientes, uma vez que estas são favorecidas pelas condições de alta luminosidade, fato ausente ou muito pouco nas condições destes quatro ambientes onde se deu a coleta do material. Além disso, a periodicidade de produção de sementes das espécies arbóreas presentes na área, a síndrome de dispersão, presença de dormência nas sementes, longevidade e predação, dentre outros fatores, afetam diretamente o depósito de sementes destas espécies em uma determinada área.

Ribeiro et al. (2017) avaliando a diversidade do banco de sementes em diferentes áreas de Caatinga manejadas no semiárido da Paraíba, encontraram valores semelhantes aos deste estudo (45 espécies e 22 famílias botânicas). É importante ressaltar que apesar dessas áreas serem manejadas, as mesmas foram impactadas anteriormente com a retirada da vegetação nativa. Porém receberam plantios homogêneos com espécies nativas do bioma em destaque. Já no presente estudo, a retirada da vegetação ocorreu de acordo com as técnicas de manejo sustentável estabelecidas para cada área, considerando as características e particularidades preconizadas para a exploração, tais como, corte seletivo e isenção de corte de espécies protegidas por lei e árvores matrizes. Provavelmente esses fatores foram decisivos na diferenciação dos resultados do presente estudo, em relação às observações e constatações, inferidas por Araújo et al. (2014) e Mendes et al. (2014).

Quanto ao número de espécies, as famílias que apresentaram maior quantidade foram: Euphorbiaceae ( 6 espécies), Malvaceae (5 espécies), Poaceae (4 espécies), Fabaceae (4 espécies), Amaranthaceae (3 espécies), Portulacaceae (3 espécies) e Convolvulaceae (3 espécies).

Quanto ao hábito das espécies identificadas, as herbáceas foi o grupo mais representativo, com $65,3 \%$ do total (32/49 espécies). Os arbustos e árvores representam, respectivamente, $8,1 \%$ (4/49 espécies) e 10,4\% (5/49 espécies) do total. Já trepadeiras e subarbustos tiveram valores de $8,1 \%$ e $8,1 \%$ (4/49 espécies), respectivamente.

A predominância do estrato herbáceo em estudos banco de sementes foi relatada por Paz, Silva e Almeida-Cortez (2016), que encontraram valores de $85,65 \%$ pertencentes ao hábito herbáceo em três áreas com diferentes graus de antropização. Subarbustos e árvores representaram respectivamente $16,13 \%$ e $3,23 \%$ do valor total. Gonçalves et al. (2011) registraram $80 \%$ de espécies herbáceas seguida por arbustos (16\%) e arbóreos (4\%) em área de caatinga invadida por Parkinsonia aculeata L. Sousa et al. (2017), de maneira semelhante notaram que $95 \%$ dos indivíduos também representavam as herbáceas.

Segundo Araújo et al. (2004), esses resultados podem ser justificados, porque as sementes de espécies herbáceas espontâneas têm a função de ocupar áreas degradadas, reiniciando o processo de sucessão desde os primeiros estágios de colonização. Araújo et al. (2001), ressaltam que as ervas são as primeiras a se dispersarem, dando origem ao processo inicial de sucessão, criando assim, condições para que ocorra a restauração seguinte com as diferentes formas de vida (arbustiva e arbórea).

As espécies arbóreas Pseudobombax marginatum, Piptadenia stipulacea e Myracrodruon urundeuva se destacaram com o número de indivíduos (3, 6 e 19, respectivamente). Esta quantidade de indivíduos e espécies arbóreas se dá provavelmente devido ao bom estado de conservação das unidades experimentais. Outrossim, é que as áreas estão sob plano de 
manejo florestal sustentável, onde as técnicas aplicadas nesses ambientes proporcionam uma maior sustentabilidade regenerativa para os indivíduos presentes.

As espécies arbóreas e arbustivas aqui descritas confirmam o sucesso do processo regenerativo através do mecanismo de resiliência. Em um estudo cujo objetivo foi analisar a resposta da regeneração às técnicas de manejo sustentável, assim como o comportamento dessas após o distúrbio ocasionado pelo corte, as espécies aqui citadas foram encontradas nas diferentes classes de altura o que fortalece mais ainda a importância de estudos que visem adquirir informações sobre o banco de sementes, sobretudo em áreas submetidas ao manejo florestal (Almeida, 2014).

\section{Diversidade florística}

A diversidade de Shannon-Weaver $\left(\mathrm{H}^{\prime}\right)$, encontrada para as quatros unidades experimentais foram: 2,33 nats. ind ${ }^{-1}$, 0,99 nats.ind ${ }^{-1}$, 2,19 nats.ind ${ }^{-1}$ e 1,35 nats.ind ${ }^{-1}$ para $R L$, UPA 2007, UPA 2012 e UPA 2014, respectivamente (Tabela 3).

Tabela 3. Índice de diversidade de Shannon-Wiener ( $\left.\mathrm{H}^{\prime}\right)$, Índice de Eqüabilidade de Pielou (J') e número de espécies das amostras de (serapilheira+solo) nas unidades de produção anuais (UPA's) e Reserva Legal em uma área submetida a plano de manejo sustentável, Cuité-PB

\begin{tabular}{ccccc}
\hline Índices & $\mathbf{R L}$ & UPA 2007 & UPA 2012 & UPA 2014 \\
\hline $\mathrm{H}^{\prime}$ & 2,33 & 0,96 & 2,19 & 1,35 \\
$\mathrm{~J}$ & 0,71 & 0,31 & 0,65 & 0,41 \\
$\mathrm{~S}$ & $26 \mathrm{a}$ & $22 \mathrm{a}$ & $28 \mathrm{a}$ & $27 \mathrm{a}$
\end{tabular}

Valores na última linha seguidos pela mesma letra não diferem estatisticamente pelo Teste de Tukey (5\% de significância).

De maneira geral os resultados referentes ao índice de diversidade de Shannon variaram de $\left(2,83,3,017\right.$ e 2,785 nats. ind $\left.{ }^{-1}\right)$ para três áreas estudadas por Gonçalves et al. (2011), (0,43, 1,99 e 3,02 nats. ind-1), para os três ambientes avaliados por Fabricante et al. (2016) e (3,03 e 2,04 nats. ind $\left.^{-1}\right)$ correspondente as duas áreas sendo uma invadida por Cryptostegia madagascariensis. Já Ribeiro et al. (2017) encontraram valores de (2,54, 2,22 e 2,31 nats. ind ${ }^{-1}$ ) respectivamente para área com plantio de craibeira, área degradada e área com plantio de jurema+sabiá. Salienta-se que embora a RL não tenha apresentado o maior número de espécies, sendo que as UPA's 2014 e 2012 apresentaram os maiores valores, o índice de Shannon foi maior para a mesma. Isso se deu devido à baixa equabilidade apresentada pela UPA 2014, sendo esta atribuída a grande abundância de indivíduos em um pequeno número de espécies.

Comportamento semelhante a esse foi observado por Sousa et al. (2017), que avaliando a influência da invasão biológica da Cryptostegia madagascariensis sobre o banco de sementes do solo, enfatizaram que devido o índice de Shannon levar em consideração a riqueza e a abundância, os resultados apresentados pelo mesmo nem sempre significam que um maior valor no número de espécies, necessariamente impliquem em um alto índice de Shannon. Os valores aqui encontrados quando analisado estatisticamente pelo teste Tukey a $5 \%$ de significância o número de espécies não se diferenciou entre as unidades experimentais.

Os valores referentes ao índice de Pielou foram de 0,71, 0,31, 0,65 e 0,41 para a RL, UPA 2007, UPA 2012 e UPA 2014, respectivamente (Tabela 3). Quando analisados juntamente com o índice de Shannon, pode-se interpretar de forma mais precisa a variação na comunidade vegetal, desde a riqueza até a distribuição de indivíduos por espécies. Aqui percebe-se claramente a influência da distribuição dos indivíduos por espécies, onde os menores valores implicam diretamente numa menor uniformidade.

Os valores 0,69, 0,67 e 0,59, encontrados por Gonçalves et al. (2011), correspondentes a três áreas com diferentes características, sendo a primeira invadida por Parkinsonia aculeata, a segunda, com possibilidade de alagamento sazonal e a terceira em bom estado de conservação. Ribeiro et al. (2017) comparando a composição florística do banco de sementes 
do solo de três áreas diferentes, chegaram a resultados para o índice de Pielou, cujos valores foram: 0,80, 0,62 e 0,82 respectivamente para área com plantio de craibeira, área degradada e área com plantio de jurema preta+sabiá.

É importante destacar os valores baixos apresentados pelas UPA's 2007 e 2014 que foram de 0,31 e 0,41 . Os baixos valores dessas duas unidades experimentais estão relacionados com a falta de uma distribuição mais homogênea do número de indivíduos por espécies.

Através do índice de Similaridade de Søresen é possível identificar semelhanças entre duas comunidades diferentes (Tabela 4).

Tabela 4. Índice de Similaridade de Søresen entre as amostras de (serapilheira+solo) nas unidades de produção anuais (UPA's) e Reserva Legal em uma área submetida a plano de manejo sustentável, Cuité-PB

\begin{tabular}{ccccccc} 
índ. & $\begin{array}{c}\text { RL/UPA } \\
\mathbf{2 0 0 7}\end{array}$ & $\begin{array}{c}\text { RL/UPA } \\
\mathbf{2 0 1 2}\end{array}$ & $\begin{array}{c}\text { RL/ UPA } \\
\mathbf{2 0 1 4}\end{array}$ & $\begin{array}{c}\text { UPA2007/ } \\
\text { UPA 2012 }\end{array}$ & $\begin{array}{c}\text { UPA2007/UPA } \\
\mathbf{2 0 1 4}\end{array}$ & $\begin{array}{c}\text { UPA2012/UPA } \\
\mathbf{2 0 1 4}\end{array}$ \\
\hline SO & 0,46 & 0,56 & 0,60 & 0,44 & 0,57 & 0,62 \\
\hline
\end{tabular}

A maior porcentagem de similaridade florística entre as unidades experimentais, foi observada entre a UPA 2012 e UPA 2014, cujo valor foi de 0,62 os demais resultados podem ser observados na Tabela 4. Pode-se inferir que as práticas de manejo não afetaram a composição florística, isso devido as estratégias adotadas tais como: cuidados no corte da vegetação, manutenção de matrizes para facilitar a dispersão de sementes, isenção de corte de algumas espécies protegidas por lei e isolamentos das áreas contra o pastejo animal. Outro fator que pode influenciar tal comportamento é o tempo em que as UPA's estão em (pousio).

Os menores valores ocorreram entre os bancos de sementes das unidades experimentais estudadas, a citar RL/UPA2007 com valor de 46\% e UPA2007/UPA2012 cujo valor foi de $44 \%$, embora esses valores sejam menores, não necessariamente indicam baixa similaridade, pois resultados maiores ou iguais a 50\% são citados por Sabino et al. (2016), como sendo um bom indicativo de alta similaridade.

\section{CONCLUSÕES}

Todos os ambientes estudados apresentam comportamento semelhante para a germinação. O banco de sementes nas três áreas de Caatinga manejadas e Reserva legal é composto predominantemente por sementes de espécies herbáceas.

O manejo florestal influencia a densidade do banco de sementes do solo.

O manejo florestal não afetou riqueza florísticas entre as unidades experimentais.

\section{REFERÊNCIAS}

Almeida, F. C. P. (2014). Estrutura e regeneração natural em remanescentes de caatinga sob manejo florestal, Cuité-PB (Dissertação de mestrado). Universidade Federal de Campina Grande, Patos.

Andrade, L. A. (2013). Plantas invasoras: espécies vegetais exóticas invasoras da Caatinga e ecossistemas associados (100 p.). Areia: Epgraf.

Angiosperm Phylogeny Group - APG III. (2009). Anupdate of the Angiosperm Phylogeny Group classification for theorders and families of flowering plants: APG III. Botanical Journal of the Linnean Society, 161p, 105-121. Recuperado em 20 de junho de 2017, de http://reflora.jbrj.gov.br/downloads/LAPG.pdf

Araújo, M. M., Longhi, S. J., Barros, P. L. C., \& Brena, D. A. (2004). Caracterização da chuva de sementes, banco de sementes no solo e banco de plântulas em floresta estacional decidual ripária Cachoeira do Sul, RS, Brasil. Scientia Forestalis, 66, 128-141. Recuperado em 10 de dezembro de 2017, de http://www.ipef.br/publicacoes/scientia/nr66/cap13.pdf

Araújo, V. K. R., Santos, D. M., Santos, J. M. F. F., Silva, K. A., Souza, D. N. N., \& Araújo, E. L. (2014). Influência do status da floresta e da variação sazonal sobre o banco de sementes no semiárido brasileiro. Gaia Scientia, 8(1), 136-149. http://periodicos.ufpb.br/ojs2/index.php/gaia/index

Araújo, M. M., Oliveira, F. A., Vieira, I. C. G., Barros, P. L. C., \& Lima, C. A. T. (2001). Densidade e composição florística do banco de sementes do solo de florestas sucessionais na região do Baixo 
Rio Guamá, Amazônia Oriental. Scientia Forestalis, 59, 115-130. Recuperado em 10 de dezembro de 2017, de

http://repositorio.museugoeldi.br:8080/bitstream/mgoeldi/268/1/Scientia\%20Forestalis\%20n59\%20 2001\%20ARAUJO.pdf

Bakke, I. A., Bakke, O. A., Andrade, A. P., \& Salcedo, I. H. (2006). Regeneração natural da Jurema Preta em áreas sob pastejo de bovinos. Revista Caatinga, 19(3), 228-235. Recuperado em 20 de junho de 2017, de http://periodicos.ufersa.edu.br/revistas/index. php/sistema/article/viewFile/77/45

Baskin, C. C., \& Baskin, J. M. (2005). Seed dormancy in trees of climax tropical vegetation types. Tropical Ecology, 46(1), 17-28. Recuperado em 10 de dezembro de 2017, de http://www.tropecol.com/pdf/open/PDF_46_1/46102.pdf

Costa, R. C., \& Araújo, F. S. (2003). Densidade, germinação e flora do banco de sementes do solo no final da estação seca, em uma área de Caatinga, Quixadá, CE. Acta Botanica Brasílica, 17(2), 259-264. http://dx.doi.org/10.1590/S0102-33062003000200008.

Fabricante, J. R., Araújo, K. C. T., Castro, R. A., \& Cotarelli, V. M. (2016). Banco de sementes do solo de sítios de Caatinga sob influência do Projeto de Integração do Rio São Francisco. Scientia Plena, 12(4), 1-9. http://dx.doi.org/10.14808/sci.plena.2016.041001.

Ferreira, C. D., Souto, P. C., Lucena, D. S., Sales, F. C. V., \& Souto, J. S. (2017). Fitossociologia do banco de sementes em diferentes estágios de regeneração natural de caatinga, Seridó paraibano. Agropecuária Científica no Semiárido, 12(3), 301-318. Recuperado em 10 de dezembro de 2017, de http://revistas.ufcg.edu.br/acsa/index.php/ACSA/index

Ferreira, C. D., Souto, P. C., Lucena, D. S., Sales, F. C. V., \& Souto, J. S. (2014). Florística do banco de sementes no solo em diferentes estágios de regeneração natural de Caatinga. Agrária, 9(4), $562-$ 569. http://dx.doi.org/10.5039/agraria.v9i4a4497.

Gonçalves, G. S., Andrade, L. A., Forte, K. R. X., Oliveira, L. S. B., \& Moura, M. A. (2011). Estudo do banco de sementes do solo em uma área de caatinga invadida por Parkinsonia aculeata L. Revista Brasileira de Biociências, 9(4), 428-436. Recuperado em 10 de dezembro de 2017, de http://www.ufrgs.br/seerbio/ojs/index.php/rbb/article/view/1440

Golos, P. J., \& Dixon, K. W. (2014). Waterproofing topsoil stockpiles minimizes viability decline in the soil seed bank in an arid environment. Restoration Ecology, 22(4), 495-501. http://dx.doi.org/10.1111/rec.12090.

Jacomine, P. K. T., Ribeiro, M. R., Montenegro, J. O., Silva, A. P., \& Melo Filho, H. F. R. (1972). Levantamento exploratório: reconhecimento de solos do estado da Paraíba. Rio de Janeiro: Ministério da Agricultura (EPFS)/SUDENE (DRN).

Jardim Botânico do Rio de Janeiro - JBRJ. (2020). Flora do Brasil 2020 em construção. Rio de Janeiro: JBRJ. Recuperado em 18 de janeiro de 2018, de http://floradobrasil.jbrj.gov.br/

Lucena, M. S., Silva, J. A., \& Alves, A. R. (2016). Regeneração natural do estrato arbustivo-arbóreo em área de Caatinga na Estação Ecológica do Seridó- RN, Brasil. Revista Biotemas, 29(2), 17-31. http://dx.doi.org/10.5007/2175-7925.2016v29n2p17.

Martins, C. R., Hay, J. D. V., Walter, B. M. T., Proença, C. E. B., \& Vivaldi, L. J. (2011). Impacto da invasão e do manejo do capim-gordura (Melinis minutiflora) sobre a riqueza e biomassa da flora nativa do Cerrado sentido restrito. Revista Brasileira de Botânica, 34(1), 73-90. http://dx.doi.org/10.1590/S0100-84042011000100008.

Martins, S. V., Rodrigues, R. R., Gandolfi, S., \& Calegari, L. (2012). Sucessão ecológica: fundamentos e aplicações na restauração de ecossistemas florestais. In S. V. Martins (Ed.), Ecologia de florestas tropicais do Brasil (2. ed., Cap. 1, pp. 21-52). Viçosa: UFV. .

Mendes, L. B., Silva, K. A., Santos, D. M., Albuquerque, U. P., \& Araújo, E. L. (2014). What happens to the soil seed bank 17 years after clear cutting of vegetations? Revista de Biología Tropical, 63(2), 321-332.

Nóbrega, A. M. F., Valeri, S. V., Paula, R. C., Pavani, M. C. M. D., \& Silva, S. A. (2009). Banco de sementes de remanescentes naturais e de áreas reflorestadas em uma várzea do Rio Mogi Guaçu - SP. Revista Árvore, 33(3), 403-441. http://dx.doi.org/10.1590/S0100-67622009000300002.

Parente, R. G., Barbosa, L. G., Souza, O. C., \& Vilar, F. C. R. (2011). Composição florística do banco de sementes do solo da caatinga em perímetro irrigado de Petrolina - PE. Revista Semiárido de Visu, 1(1), 18-31. Recuperado em 10 de dezembro de 2017, de http://www.periodicos.ifsertaope.edu.br/ojs2/index.php/revista/article/view/29

Pareyn, F., Vieira, J. L., \& Gariglio, M. (2015). Estatística florestal da Caatinga (Vol. 2, 142 p.). Recife: Associação Plantas do Nordeste. 
Paz, G. V., Silva, K. A., \& Almeida-Cortez, J. S. (2016). Banco de sementes em áreas de caatinga com diferentes graus de antropização. Journal of Environmental Analysis and Progress, 1(1), 61-69. http://dx.doi.org/10.24221/jeap.1.1.2016.987.61-69.

Ribeiro, T. D. O., Bakke, I. A., Souto, P. C., Bakke, O. A., \& Lucena, D. D. S. (2017). Diversidade do banco de sementes em diferentes áreas de caatinga manejadas no semiárido da Paraíba, Brasil. Ciência Florestal, 27(1), 203-213. http://dx.doi.org/10.5902/1980509826459.

Riegelhaupt, E., Pareyn, F. G. C., \& Bacalini, P. O. (2010). Manejo florestal na Caatinga: resultados da experimentação. In M. A. Gariglio, E. V. S.B. Sampaio, L. A. Cestaro \& P. Y. Kageyama (Eds.), Uso sustentável e conservação dos recursos florestais da caatinga (pp. 256-275). Brasília: Serviço Florestal Brasileiro.

Sabino, F. G. S., Cunha, M. C. L., \& Santana, G. M. (2016). Estrutura da Vegetação em Dois Fragmentos de Caatinga Antropizada na Paraíba. Floresta e Ambiente, 14(1), 26-37. http://dx.doi.org/10.1590/21798087.017315.

Santos, D. M., Silva, K. A., Santos, J. M. F. F., Lopes, C. G. R., Pimentel, R. M. M., \& Araújo, E. L. (2010). Variação espaço-temporal do banco de sementes em ama área de floresta tropical seca (caatinga) pernambuco. Revija za Geografijo, 27(1), 234-253.

Santos, H. G., Jacomine, P. K. T., Anjos, L. H. C., Oliveira, V. A., Lumbreras, J. F., Coelho, M. R., Almeida, J. A., Cunha, T. J. F., \& Oliveira, J. B. (2013). Sistema brasileiro de classificação de solos (3. ed. rev. ampl., 353 p.). Brasília: Embrapa.

Santos, D. M., Silva, K. A., Araújo, V. K. R., \& Araújo, E. L. (2016). Composition, species richness, and density of the germinable seed bank over 4 years in young and mature forests in Brazilian semiarid regions. Journal of Arid Environments, 129, 93-101. http://dx.doi.org/10.1016/j.jaridenv.2016.02.012.

Schippers, P., Van Groenendael, J. M., Vleeshouwers, L. M., \& Hunt, R. (2001). Herbaceous plant strategies in disturbed habitats. Oikos, 95(2), 198-210. http://dx.doi.org/10.1034/j.16000706.2001.950202.x.

Schorn, L. A., Fenilli, T. A. B., Krüger, A., Pellens, G. C., Budag, J. J., \& Nadolny, M. C. (2013). Composição do banco de sementes no solo em áreas de preservação permanente sob diferentes tipos de cobertura. Floresta, 43(1), 49-58. http://dx.doi.org/10.5380/rf.v43i1.21493.

Silva, F. A. S., \& Azevedo, C. A. V. (2016). The Assistat Software Version 7.7 and its use in the analysis of experimental data. African Journal of Agricultural Research, 11(39), 3733-3740. http://dx.doi.org/10.5897/AJAR2016.11522.

Silva, J. A. (1994). Avaliação do estoque lenhoso: inventário florestal do Estado da Paraíba (Documento de Campo, No. 21, 27 p.). João Pessoa: PNUD/FAO/IBAMA/Governo da Paraíba.

Sousa, F. Q., Andrade, L. A., Silva, P. C. C., Souza, B. C. Q., \& Xavier, K. R. F. (2017). Banco de sementes do solo de caatinga invadida por Cryptostegia madagascariensis Bojer ex Decne. Agrária, 12(2), 220-226. De http://dx.doi.org/10.5039/agraria.v12i2a5440.

Superintendência de Administração do Meio Ambiente - SUDEMA. (2004). Atualização do diagnóstico florestal do Estado da Paraíba. João Pessoa: SUDEMA. 268 p. Recuperado em 10 de dezembro de 2017, de http://sudema.pb.gov.br/

Contribuição dos Autores: MPS: Conceituação, Análise Formal, Escrita - Primeira Redação; ARA: Escrita - revisão e edição, supervisão, validação, IAB: Escrita - revisão e edição, supervisão, validação; JAL: Curadoria de Dados, Recursos, Software; WSS: Curadoria de Dados, Recursos, Software; EMPF: Curadoria de Dados, Recursos, Software. 